\title{
\begin{tabular}{llllllllll}
\hline $\mathrm{C}$ & $\mathrm{O}$ & $\mathrm{M}$ & $\mathrm{M}$ & $\mathrm{E}$ & $\mathrm{N}$ & $\mathrm{T}$ & $\mathrm{A}$ & $\mathrm{R}$ & $\mathrm{Y}$ \\
\hline
\end{tabular}
}

\section{Do Condoms in Public Schools Affect the Pregnancy Rate?}

\author{
Alan C. MacGregor, MSc
}

In deciding whether or not to make condoms available in their schools, the North Okanagan-Shuswap School District in British Columbia asked: What effect does the availability of condoms in public schools actually have on pregnancy rates? School district boundaries throughout British Columbia are generally the same as the boundaries of local health areas, with a few exceptions and with allowance for the recent school district amalgamations. Pregnancy rates (for all outcomes) for girls aged 10-14 and 15-17 years are available for the equivalent of school districts for the years 1988/89 through 1996/97.

The pregnancy rates for 10-14 year-old girls were found to be too low and erratic to show any trend. The rates for girls aged 15-17 varied tremendously from year to year, with no clear trend, whether or not the districts made condoms available. The data showed (each girl being counted as equal) that there were 28.6 pregnancies per 1,000 girls for districts without condoms available, and 32.4 for districts with. Districts with condoms available had higher pregnancy rates!

When the data were analyzed as to the increase or decrease in pregnancy rates over the nine years 1988/89 through 1996/97, the average change was a decrease of 1 pregnancy per 100,000 girls for districts without condoms and a decrease of 2 per 100,000 for districts with. In general, the larger districts had a greater decrease than the smaller, more rural districts, but the change was negligible in both cases.

Affiliated with School District \#83 (North Okanagan-Shuswap)

Correspondence and reprint requests: Mr. Alan MacGregor, 3478 Yankee Flats Rd., Salmon Arm, BC V1E 4M1, Tel: 250-379-2247, E-mail: amacgreg@cnx.net
There were a number of complicating factors in this review. As a generalization, districts with condoms tended to be in the metropolitan areas, districts without were more rural. Consequently, some of the many differences in lifestyle may contribute to the differences in rates. There is also a different population mix in some districts. This clearly influenced the pregnancy rates. Socioeconomic factors are often considered to have an influence on educational and health issues, and the same appears to hold true here. It would seem reasonable to expect that students who experience greater academic success, and so districts that do better than average academically, would then experience a lower pregnancy rate. None of these factors were checked, however, and with the tremendous variation in rates, it may not be possible to tell how much of an influence each factor was.

For many districts, condoms were introduced when or just after there was an exceptionally high pregnancy rate in that district. So, it appears that sometimes condoms might have been introduced by boards as a reaction to a high pregnancy rate, or through fear that things were getting worse and something must be done. It may cause a superficial analysis to conclude that the rates were steadily increasing, condoms were introduced, and then the rates dropped back to a low level. However, the same trend can be seen in many of the districts whether or not condoms were made available. It does not appear that condom availability was the cause of the high rates, and it certainly was no solution to high pregnancy rates. Condom availability had no net effect on school-aged pregnancy problems at all!

So, what could be learned that would be useful to decision makers? First, some peoples' expectations and claims are not realistic. This review shows that pregnancy rates are extremely variable and will not be reduced by simplistic solutions. With such variability, a simple before and after analysis of rates will show nothing that is accurate. Rates must be examined over the very long term, not just the last few years' rates, in order to find any trend. Looking at short-term rates will only deceive. Second, making condoms available will not affect the pregnancy rate. There are still many good reasons for and against condoms being available in schools, but a magic bullet they are not. It is necessary to look more carefully at the problem, and to look for solutions to the underlying problems, rather than looking at the symptoms. In trying to reduce pregnancy rates it may be necessary to actually work with young people, not just do something to them or for them. Since they are involved in the problem, they must be involved in the solution, so let's talk with them!

\section{REFERENCES}

1. British Columbia Vital Statistics Agency, Pregnancy Rates (Ages 10-14, and Ages 15-17) by Local Health Area, 1988/89 to $1996 / 97$, Vital Statistics, 1998.

2. Responses are from requests to each district's Secretary-Treasurer, or failing that, from the Superintendent. 